\title{
Towards human development friendly universities
}

\section{BO0K TITLE:}

Universities and global human development. Theoretical and empirical insights for social change

\section{BOOK COVER:}

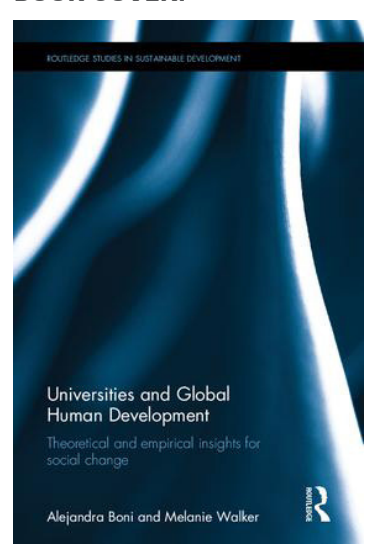

AUTHORS:

Alejandra Boni and

Melanie Walker

\section{ISBN:}

9780815355878 (softcover)

\section{PUBLISHER:}

Routledge, Abingdon; GBP36.99

\section{PUBLISHED:}

2016

\section{REVIEWER:}

Merridy Wilson-Strydom

\section{AFFILIATION:}

Centre for Research on Higher Education and Development, University of the Free State, Bloemfontein, South Africa

\section{EMAIL:}

wilsonstrydommg@ufs.ac.za

\section{HOW TO CITE:}

Wilson-Strydom M. Towards human development friendly universities. S Afr J Sci. 2018;114(5/6), Art. \#a0262, 2 pages. http://dx.doi. org/10.17159/sajs.2018/a0262

\section{PUBLISHED:}

30 May 2018

(C) 2018. The Author(s). Published under a Creative Commons Attribution Licence.
This book is timely and important for the higher education sector at local, national and global levels as well as for debates about what constitutes development and what role universities ought to have in development and social change. The authors propose a normative framework, based on human development ideas, that is of value for policymaking, scholarship and practitioners and that shows 'why higher education matters both in educational and social terms' (p. 6). Three objectives flow from this aim: (1) to deepen the link between universities and human development; (2) to operationalise human development in and through universities at a more local level; and (3) to encourage universities to question how and what knowledge is produced through research, and selected and mediated through teaching and learning within our universities. Key human development values such as participation, equity, sustainability, diversity and human security are emphasised throughout.

The book is presented in three parts. The first part sets out the relevant literature, conceptual framing, and operationalises the aims and objectives of the book. In the second part, the authors turn to empirical examples at both policy and practice levels and use these examples to question the nexus between higher education and human development. In the final part, these issues are woven together to make a 'robust but feasible case for universities, which could be for more rather than less human development and social justice in a world of growing inequalities' (p. 11).

Chapters 2 and 3 provide a helpful and critical overview of the role of universities when approached from an education and development perspective. For the reader new to the field of development studies or international development, the setting out of major development theories is useful. Chapter 4 provides a succinct and wellargued overview of the key concepts, ideas and implications of the human development and capability approaches. This chapter would be of particular value to those new to the area, but also serves as a helpful reminder of the key tenets of the approach for those who may be better versed in the ideas. The application to higher education points to the usefulness of the approach for thinking differently about universities, but also provides a helpful context within which to consider what human development ideas mean in practice.

The book then turns to policy and practice applications. These application chapters provide evidence of different ways of being and doing within universities and show why this is important. In the first application chapter, the authors analyse higher education policies from a human development point of view. Their approach to policy is a key strength of the chapter, with policy being understood in two senses: as texts (policy documents) produced by different actors and as processes of negotiation, contestation and struggle that may take place outside of the official policymaking machinery. Two quite different policy examples are interrogated - the Responsible Research and Innovation policy in the EU and Spanish context, and the 2013 White Paper for Post-School Education and Training in South Africa, with a particular focus on the section on quality.

Next, the authors turn to the knowledge and research contributions to human development that are made possible when universities pay attention to how research is conducted and the challenging epistemic questions of whose knowledge, for whose benefit and for whose capability expansion. The authors make the case not only for 'good research' - which is of course important - but instead for what they call 'good for research' - research that makes a difference in the world around us. Although less explicitly stated, the book also makes a case for 'good for higher education', as opposed to simply good higher education. These distinctions have critical implications for how we think about the purposes and quality of higher education. An important component of the argument in this chapter is the need to keep alive a commitment to university-produced knowledge as a public good, especially in a global context in which knowledge is typically approached as intellectual property not unlike other goods and services that are produced, accumulated and traded, often for financial gain.

In the following chapter, this argument becomes more concrete, with a specific focus on the potential of participatory action research (PAR) in the context of social sciences research. After setting out the key elements of PAR and reflecting on how this can support human development oriented research, Boni and Walker propose a new theoretical framework to analyse and inform PAR in higher education from a human development and capability approach point of view. In particular, they propose a 'participatory research capability cube' that has a tri-dimensional perspective, including: (1) a participatory axis that considers the expansion of the capabilities and agency of co-researchers, (2) a knowledge axis that takes account of the characteristics of the knowledge produced, and (3) a public deliberation axis that draws attention to the democratic processes that PAR can enable during and beyond a given research process. This innovative theoretical and analytical frame is then applied to understand a participatory research and teaching process that took place in the poor neighbourhood of San Lorenza in Castelon, Spain, as part of a 14-day intensive summer school for 30 master's degree students from across Europe.

The final application chapter turns to student learning opportunities and outcomes and explores how this core function of the university can be understood from a human development perspective. The argument covers curriculum and pedagogy and highlights the importance of drilling down to the micro-space of learning conditions which are shaped by wider circumstances and inequalities in society. Three cases - two initiatives in Spain centred around curriculum and citizenship, and one in South Africa focused on employability - are used to illustrate the argument. The chapter shows that 'while neoliberal times may undoubtedly make life hard in universities, there are spaces to practice education differently... and to be agents as students and lecturers, rather than onlookers to policy' (p. 172). 
In the last part of the book, Boni and Walker sum up the arguments and evidence presented across the chapters to make a case for what they call 'the human development friendly university'. This is a university that would be shaped by human development values in all dimensions of their core activities, including research, curriculum, pedagogy and policy. Although the community engagement function of the university is not explicitly considered in the book (a gap worth addressing in future work), the approach to research and to teaching and learning proposed implies meaningful engagement with actors outside of the university. To become a different type of university, a new language for thinking about universities and social change is needed. Boni and Walker propose that the human development approach could provide this different language, together with an alternative informational basis for assessing justice and social change contributions both within and beyond the university. The language of human development and capabilities enhancement provides a lexicon that could be used to challenge the current mainstream vision of a university that is based primarily on neo-liberal values. As has been shown in this book, there are exciting examples of research and teaching and learning practices that do take us in the direction of a human development friendly university - practices that meaningfully contribute to building more just and responsive universities, both within the university itself and with respect to the university's role in society.

This book is an important and challenging one that is well worth engaging with for those who wish to explore different purposes for higher education in society, and particularly for those who want to think and act differently across their various roles within the university. 